\title{
DA INVISIBILIDADE AO RECOMEÇO SOCIAL: UM ESTUDO SOBRE TRABALHADORES DO PROJETO “LUXO DO LIXO” EM CATANDUVA-SP'
}

\author{
Davis Gláucio QUINELATO² \\ Zildo GALLO ${ }^{3}$ \\ Oriowaldo QUEDA ${ }^{4}$ \\ Elizabete David NOVAES ${ }^{5}$
}

Recebido em: 26/05/2014 - Aprovado em: 30/06/2014 - Disponibilizado em: 30/07/2014

\begin{abstract}
RESUMO
Esta pesquisa pretende através da história de vida dos trabalhadores do Projeto "Luxo do Lixo", compreender as relações que permeiam seu cotidiano e entender as origens de sua exclusão social. A decisão de estudar tal tema, assim como o que leva nos dias de hoje determinado grupo de trabalhadores, que um dia perderam tudo na vida, a tentarem reconstruir suas trajetórias, trabalhando com resíduos sólidos, nos faz contribuir para o debate que busca a compreensão do real motivo que os levam a voltar a trabalhar exatamente com o descarte da população. Para isso, a metodologia da história oral apresenta-se como uma aliada, pela sua capacidade de apreender fatos notáveis e acontecimentos corriqueiros que trazem para a reflexão a noção de vida social. Apesar dos dramas e dificuldades que enfrentam, os trabalhadores vêm garantindo sua sobrevivência material e sua autoestima. A análise dos dados qualitativos da pesquisa, a partir dos trabalhadores estudados, sinaliza que uma participação autêntica em um projeto organizado, acrescida de uma intervenção do poder público, sociedade e parceiros é imprescindível para a superação da condição de exclusão.
\end{abstract}

Palavras-chave: Exclusão Social; Projeto "Luxo do Lixo"; Resíduo Sólido.

\section{ABSTRACT}

This research aims through the life history of the project workers' Luxury Garbage, understand the relationships that pervade their everyday life and understand the origins of their social exclusion. The decision to study the issue of social exclusion, as well, which leads the current workers who have lost everything in one day today life and try to rebuild their lives working just to solid waste, make us contribute to research on understanding the real reason that lead them back to work exactly with the disposal of the population. For this purpose the methodology of oral history presents itself as an ally, for his remarkable ability to grasp facts and everyday events that give us the notion of social life. Despite the tragedies and hardships they face, workers are guaranteed their material survival and self-esteem. The analysis of qualitative data from the research study indicates that workers genuine participation in an organized project, plus an intervention by the public, partners and society is essential for overcoming the exclusion condition.

Keywords: Social Exclusion; Project "Luxo do Lixo"; Solid Waste.

\footnotetext{
1 Artigo baseado na dissertação de mestrado "Da invisibilidade ao recomeço social: um estudo sobre os trabalhadores do Projeto ‘Luxo do Lixo’ em Catanduva-SP sob a orientação do Prof. Dr. Zildo Gallo, concluída no ano de 2012.

${ }^{2}$ Mestrando do Programa de Mestrado em Desenvolvimento Regional e Meio Ambiente do Centro Universitário de Araraquara - UNIARA.

${ }^{3}$ Prof. Dr. do Mestrado em Desenvolvimento Regional e Meio Ambiente do Centro Universitário de Araraquara - UNIARA.

${ }^{4}$ Prof. Dr. do Mestrado em Desenvolvimento Regional e Meio Ambiente do Centro Universitário de Araraquara - UNIARA.

${ }^{5}$ Profa. Dra. da Faculdades COC - Ribeirão Preto.
} 


\section{INTRODUÇÃO}

O Projeto "Luxo do Lixo" foi criado pela Cáritas Brasileira, entidade fundada no ano de 1956 pela Conferência Nacional dos Bispos do Brasil (CNBB), cuja finalidade inicial trataria de articular, nacionalmente, todas as obras sociais católicas e coordenar o Programa de Alimentos doados pelo governo norteamericano através da CNBB.

As questões relacionadas ao meio ambiente sempre despertam atenção e preocupação. Com isso, em decorrência da maneira pelo qual foi apresentado, percebe-se que o Projeto "Luxo do Lixo", se bem estruturado e coordenado, renderia bons frutos e, neste sentido, poder-se-ia pesquisar não só a questão ambiental, mas também a oportunidade social e o "recomeço" que envolveria famílias da comunidade de Catanduva/SP.

Nessa perspectiva, em conversas entre orientador (Davis Gláucio Quinelato) e orientando (Prof. Dr. Zildo Gallo), teve início uma investigação sobre o projeto que estava sendo desenvolvido em Catanduva. Por meio dessa troca de informações foi sugerido como assunto a ser trabalhado na dissertação de mestrado a história de vida dos trabalhadores ligados ao Projeto. Alguns deles participaram de outros programas sociais, criados e desenvolvidos pelo atual coordenador do Projeto "Luxo do Lixo", o Padre Osvaldo de Oliveira Rosa.

O trabalho de campo foi realizado em cinco etapas, durante os dias: 23 de maio, 30 de maio, 20 de julho, 02 de setembro e 09 de setembro do ano de 2011. Foram entrevistadas onze pessoas do sexo masculino e dezessete pessoas do sexo feminino, todos com mais de dezoito anos de idade e trabalhadores no Projeto "Luxo do Lixo". De trabalhador para trabalhador variaram o tempo a eles destinados. Além de entrevistas sobre a história de vida, também foram colhidos durante os depoimentos os dados sociais dos trabalhadores.

A pesquisa foi realizada com o consentimento e aprovação do Comitê de Ética em Pesquisa do Centro Universitário de Araraquara - UNIARA e para a coleta dos dados foi utilizado um gravador digital. Após a transcrição de cada entrevista, optou-se pela reorganização cronológica e lógica do texto.

Deste modo, o que segue é produto desse contato com um universo aparentemente distante, mas, de fato, bem próximo de cada um de nós. Também se buscou a independência e a transparência nos resultados colhidos. Espera-se que o resultado da pesquisa, aqui resumido neste breve artigo, seja relevante para cada leitor 
assim como foi para o pesquisador, para o orientador e para os professores das bancas de qualificação e de defesa da dissertação de mestrado, no caso os professores doutores Oriowaldo Queda e.Elizabete David Novaes.

\section{DA EXCLUSÃO SOCIAL}

"Miséria é imoral. Pobreza é imoral. Talvez seja o maior crime moral que uma sociedade possa cometer."

Herbert José de Souza (Betinho), 1935 - 1997.

Nesta parte discute-se a questão que envolve a exclusão social. Neste contexto, seja de mendigo a excluído, de marginal a trabalhador precário, de catador de material a dependentes químicos, são diversificados os significados e denominações utilizadas para designar essas pessoas, no entanto, o sentido é o mesmo.

Analisa-se que a aproximação da população com os excluídos é resultado de um processo próprio da sociedade capitalista, que é eminentemente excludente. Entretanto, não foi esquecido que a luta pela sobrevivência persegue o ser humano desde os primórdios, e o espírito que move essas pessoas, é fundamentalmente gregário. Esses dois fatores, a sobrevivência e a união, favorecem o florescimento da participação na sociedade. Assim, visualizou-se ao mesmo tempo a exclusão e a participação por uma vida melhor.

\subsection{AS CONSEQUÊNCIAS DA EXCLUSÃO SOCIAL}

O termo exclusão social teve origem na França, no modo francês de classificação social e neste caso, especificamente, relacionado com pessoas ou grupos desfavorecidos. Assim, o termo de origem francesa toma vulto, a partir do livro Les Exclus, de autoria de Lenoir (1974), que define os excluídos "como aqueles indivíduos concebidos como resíduos dos trinta anos gloriosos de desenvolvimento".

$\mathrm{O}$ escritor e político brasileiro Cristovam Buarque (in Nascimento, 1996), ao analisar a crise econômica que pairava à época, publica escritos (1991, 1993 e 1994) que chamam a atenção para a ameaça à paz social. Segundo Buarque, "a exclusão social passa a ser vista como um processo presente, visível e que ameaça confinar grande parte da população numa apartação social informal" (BUARQUE, apud Nascimento, 1996, p. 69).

Para o autor, fica evidente a divisão entre pobre e rico, em que o pobre é miserável e ousado, enquanto o outro se 
caracteriza como o rico minoritário e temeroso.

Os trabalhadores envolvidos com o resíduo sólido por estarem em condições de inferioridade na hierarquia social são, muitas vezes, tratados e considerados como "não-semelhantes", como sendo o fenômeno de separar o outro, não mais considerado como humano, na melhor forma, foi utilizado para indicar o desenvolvimento separado entre incluídos e excluídos (BUARQUE,2001, p.33).

No que diz respeito às condições de vida dos trabalhadores, Robert Castel (1998, p. 516) sugere aprofundar a compreensão do que vem ocorrendo por meio da reconstituição da vulnerabilidade social, conceituando-a em dois eixos principais: o do trabalho e o das relações de sociabilidade.

\subsection{VIDAS DE RUA}

A presença de adultos vivendo cotidianamente nas ruas é uma realidade universal, notadamente, nas grandes metrópoles com processos de urbanização mais ou menos planejados, mais antigos ou mais recentes. Tal fenômeno tem questionado profissionais, pesquisadores, organizações não-governamentais (ONGs) e, especialmente, as políticas públicas. Neste sentido, a pesquisadora Cleisa Moreno Maffei Rosa (2005), em sua obra Vidas de Rua, busca responder o motivo pelo qual as pessoas usam as ruas para morar e sobreviver.

Os primeiros grupos a interagirem com a população de rua ocuparam-se da construção de conceitos que legitimassem ou expressassem determinada prática em relação a ela, contando inclusive com a participação de grupos religiosos. A autora relata, com propriedade em seu trabalho, que a mudança freqüente de terminologias aponta para a fragilidade de conceitos, destinados a abranger toda a complexidade, a dramaticidade do sofrimento e perdas reais das pessoas que vivem na rua.

No que diz respeito às histórias de vida dos moradores de rua entrevistados, que contadas em pormenores ao descrever as agruras e alegrias pelas quais passa a população em situação de rua, expressam o cuidado que a autora dedica ao grupo de pessoas, sem perder de vista a individualidade e a identidade dos que compõem os grupos que vivem nas ruas.

Vivem no limite da possibilidade de uso da bebida ou da droga ilícita, pela falta de perspectiva e de saídas; como também ficam à mercê de traficantes, que intencionam fazer dos moradores de rua usuários ou passadores e utilizá-los para acertos de contas entre eles próprios. 
Visando uma reflexão humana, analisa-se que o refugo humano é tratado da mesma forma que o lixo doméstico, vislumbra-se que essas produções prosseguem inquebráveis e atingem novos ápices. A consequência disso é que o planeta passa, rapidamente, a precisar de locais de despejo e de ferramentas para a reciclagem do lixo e de gente.

\section{PROJETO “LUXO DO LIXO”}

"Quando uma criatura humana desperta para um grande sonho $e$ sobre ele lança toda a força de sua alma, todo o universo conspira a seu favor”.

Johann Goethe, 1749 - 1832.

Nesta parte explicita-se a questão que envolve a história do Projeto "Luxo do Lixo", desde a sua implantação no Brasil pela instituição Cáritas - que é ligada à Igreja Católica - até o seu desenvolvimento no âmbito municipal, no município de Catanduva/SP, cuja instituição mantenedora é a Associação "Pão Nosso - Obras Sociais Padre Osvaldo".

\subsection{PROJETO LUXO DO LIXO NO} BRASIL

No ano de 1991 foi iniciado o processo de elaboração do $1^{\circ}$ Regimento Interno do Regional, concluído em 1993, após a participação de todas as entidadesmembro. Nesse período, o Regional São Paulo instalou o primeiro aparelho de FAX em toda a rede Cáritas no Brasil. Em 1992, começa a ser implantado o Projeto "Luxo do Lixo", Esperança de Vida Nova, com catadores de papel e moradores de rua, bem como para atender a desempregados.

$\mathrm{O}$ projeto contou com a participação de 12 Cáritas (Arqui) Diocesanas, sendo apoiado, no primeiro momento, pelas Cáritas Internacionais da Alemanha - Sours Catholique - Cáritas França, Cáritas Holandesa, Cáritas Italiana e Cáritas Suíça. Depois, esse projeto seguiu com o apoio da Cáritas Alemã, com recursos do Governo Alemão. A experiência do projeto foi apresentada na Conferência das Organizações NãoGovernamentais - (ONGs), da Rio 92 ECO 92, da qual participaram a Cáritas Brasileira e também a CNBB. No ano de 1996, o Regional de São Paulo é reativado como Secretariado Regional filial da Cáritas Brasileira, jurídica e oficialmente. Nesse momento, a Cáritas alemã, através de recursos do Governo Alemão, passa a 
apoiar o Projeto "Luxo do Lixo" e o Regional de São Paulo (1993-1998). Características da instituição: a Cáritas Brasileira/ Regional de São Paulo é um organismo da Confederação Nacional dos Bispos do Brasil (CNBB); seu projeto "Luxo do Lixo" nasceu da experiência em Guaratinguetá, da Obra Social "Nossa Senhora da Glória", que com a atividade de reciclagem busca a recuperação de drogados e presidiários. Da necessidade de desenvolver um trabalho autossustentado, combinado com as atividades de promoção humana, 12 dioceses da Cáritas do Brasil e Estado de São Paulo iniciaram o programa de coleta seletiva em 1991.

\subsection{PROJETO LUXO DO LIXO EM CATANDUVA}

O Projeto "Luxo do Lixo" nasceu por iniciativa do Poder Executivo de Catanduva, através de Lei $\mathrm{n}^{\circ} 3449$, de 10 de novembro de 1998, em convênio com a Cáritas Diocesana de São José do Rio Preto e a Associação dos Catadores de Papel, Papelão e Materiais Recicláveis de Catanduva.

A Lei que criou o Projeto "Luxo do Lixo" foi publicada nos Classificados de “O Regional", datada de 12/10/1998. No entanto, a primeira reunião entre os membros do Poder Executivo e a Cáritas
Diocesana de São José do Rio Preto, para assinatura do convênio, foi somente no ano de 1999, mais precisamente no mês de fevereiro. O Projeto "Luxo do Lixo" fez parte do Programa de Geração de Emprego e Renda do governo municipal de Catanduva, na gestão do Prefeito Félix Sahão Júnior, do Partido dos Trabalhadores (PT).

A parceria inicial previa o recolhimento e coleta dos resíduos recicláveis por parte da Associação que levaria até o barracão da Companhia de Entrepostos e Armazéns Gerais de São Paulo (CEAGESP), onde estariam as máquinas para prensar resíduos sólidos e outros equipamentos. A Cáritas fornece as máquinas necessárias e conhecimento sobre o trabalho. A empresa de coleta de resíduos sólidos do município também se dispôs a auxiliar, inicialmente, o recolhimento de resíduos recicláveis em alguns bairros da cidade. O Projeto "Luxo do Lixo" foi oficialmente inaugurado no dia 23 de junho do ano de 1999. A inauguração foi bastante concorrida e recebeu destaque de toda imprensa.

$$
\text { É importante ressaltar que, o }
$$
Projeto "Luxo do Lixo" passou por sérias dificuldades a ponto de deixar de funcionar como cooperativa, vindo a ganhar força e novos estímulos depois que, sob a direção do Padre Osvaldo de Oliveira Rosa, a 
Associação "Pão Nosso" assumiu a iniciativa de forma mais profissional, acreditando que investir no "Luxo do Lixo" seria uma forma de aliar sustentabilidade ambiental e assistência social.

No primeiro ano desta nova fase do Projeto Luxo do Lixo, ou seja, em 2009, foram criadas 15 novas vagas de emprego, totalizando 23 trabalhadores que recebem anotação de registro na Carteira de Trabalho e Previdência Social (CTPS), além de uma cesta básica mensal. Também foram realizados vários investimentos novos, tais como: compra de veículo para coleta do material reciclável, manutenção em todos os equipamentos de produção e reforma geral do veículo cedido pela Cáritas Diocesana.

O Projeto "Luxo do Lixo" tem sede de funcionamento localizada à Rua São Paulo, $\mathrm{n}^{\circ} 888$, na cidade de Catanduva, estado de São Paulo. Os trabalhadores engajados no Projeto, desde o tempo da Cooperativa, também foram registrados pela Associação "Pão Nosso - Obras Sociais Padre Osvaldo", que passou a fornecer uniformes, equipamentos de proteção individuais e treinamentos sobre segurança e higiene do trabalho. Os trabalhadores têm o acompanhamento de uma empresa especializada em segurança preventiva de trabalho, denominada
Instituto de Medicina e Segurança do Trabalho SC Ltda. (INSMED Catanduva). Segundo Padre Osvaldo de Oliveira Rosa (2011), a empresa oferece cursos de capacitação, palestras incluindo autoestima, apoio médico e assistente social. A Faculdade de Tecnologia de São Paulo (FATEC), com uma unidade em Catanduva, realizou com o Projeto "Luxo do Lixo" um curso de liderança aos trabalhadores.

Atualmente, o Projeto possui 33 trabalhadores registrados, sendo que 28 estão diretamente ligados à coleta, separação e prensa do material coletado, dois são coordenadores e três são motoristas contratados. De acordo com, Padre Osvaldo de Oliveira Rosa (2011), “o objetivo do Projeto "Luxo do Lixo" é empregar e resgatar pessoas que estão passando por dificuldades e fora do mercado de trabalho, ou seja, que não tiveram oportunidades".

\section{3 - A FALA DOS TRABALHADORES}

"Não é no silêncio que os homens se fazem, mas na palavra, no trabalho, na ação-reflexão".

Paulo Freire, 1921-1997

Nesta parte segue o relato de uma amostra de trabalhadores envolvidos no 
Projeto "Luxo do Lixo" e um conjunto de entrevistas sobre a história de vida de cada um deles, depoimentos que constituem a trajetória de vida e experiências próprias vividas e partilhadas.

As entrevistas deram oportunidade para que estes trabalhadores pudessem falar sobre si mesmos, sobre como eles encaram a sociedade e sobre a visão que têm de sua participação como indivíduos. Em sua versão transcrita, apresentam elementos básicos para a compreensão do agir - pensar - sentir dos trabalhadores.

\subsection{A FALA DOS} TRABALHADORES: HOMENS E MULHERES DO PROJETO "LUXO DO LIXO”

Neste trabalho de campo, realizado com os trabalhadores do Projeto "Luxo do Lixo" no próprio barracão do café, local de funcionamento do Projeto, os entrevistados foram homens e mulheres, com idade entre 23 e 57 anos. Entre eles haviam pessoas casadas, solteiras, separadas e divorciadas, em sua maioria professantes da fé católica e evangélica, tendo como estado de origem São Paulo.

A partir dos depoimentos dos entrevistados, que fazem parte deste estudo de caso - depoimentos estes que podem ser considerados como livres, espontâneos e simples - a busca será compreender a maneira como esses trabalhadores vivem e fazem do Projeto "Luxo do Lixo" um recomeço e um novo caminhar em suas vidas, vidas marcadas profundamente por sofrimentos, decepções e baixas relacionadas ao consumo de álcool e drogas.

Antes de dar voz a estes trabalhadores, foram retratados - através de uma avaliação quantitativa dos questionários aplicados aos 28 trabalhadores - alguns traços de suas formas de ser e viver. A avaliação segue abaixo.

O Projeto "Luxo do Lixo" é composto por 28 trabalhadores, 11 homens (40\%) e 17 mulheres (60\%). Entre os homens entrevistados, um respondeu como opção sexual ser homossexual e o outro bissexual. As respostas foram analisadas por gênero para verificar se, neste caso, existem diferenças significativas das respostas.

Entre o gênero masculino, a maioria, ou seja, oito trabalhadores, são praticantes da religião Católica; apenas 2 trabalhadores declararam ser evangélicos, pertencentes às respectivas Igrejas: "Assembleia de Deus" e "Deus é Amor"; e um trabalhador disse ser espírita Kardecista. Entre o gênero feminino, oito mulheres são católicas, oito evangélicas e 
um não informou a religião. Entre as mulheres evangélicas, cinco pertencem à denominação "Assembleia de Deus", duas à Igreja "Deus é Amor" e apenas uma à Igreja "Universal do Reino de Deus".

No gênero masculino, cinco trabalhadores pertencem à faixa etária que varia entre 41 e 50 anos, enquanto que no gênero feminino nove trabalhadoras entrevistadas pertencem à faixa etária que varia entre 41 e 50 anos. Percebe-se uma ligeira diferença de idade que se revela superior no gênero masculino, sobrepondose ao gênero feminino.

A escolaridade declarada, entre os trabalhadores, pareceu retratar a realidade; no gênero feminino, duas trabalhadoras responderam que são analfabetas, mas souberam escrever seus nomes.

No caso do estado civil, entre os trabalhadores do gênero masculino, cinco disseram ser solteiros, o correspondente a $46 \%$ e apenas dois trabalhadores declararam ser separados. Enquanto que, no gênero feminino, 10 trabalhadoras responderam que são solteiras, o correspondente a $59 \%$ e apenas quatro trabalhadoras responderam ser amasiadas, divorciadas ou separadas.

Entre os trabalhadores do gênero masculino, a televisão é a principal fonte de informação, o que corresponde a quase $90 \%$ dos entrevistados. No gênero feminino, 16 trabalhadoras responderam que a principal fonte é a televisão e somente uma trabalhadora declarou receber suas informações via rádio. Quanto ao Estado de origem, entre os trabalhadores do gênero masculino, 10 entrevistados, o correspondente a 91\%, responderam ser de cidades do Estado de São Paulo, dentre elas: Catanduva, Taquaritinga, Urupês, Cotia e São Paulo, capital. Apenas um trabalhador respondeu ser do estado do Paraná. Quanto ao gênero feminino, 16 trabalhadoras responderam ter como lugar de origem alguma cidade do Estado de São Paulo, dentre elas: Catanduva, Novais, Olímpia, Itajobi, Pindorama, Presidente Prudente, Severínia e Tanabi, o que corresponde a $94 \%$ das entrevistadas. Apenas uma trabalhadora respondeu ser do estado da Bahia.

Entre os trabalhadores do gênero masculino, quando perguntados sobre a origem do primeiro trabalho, nove trabalhadores responderam que foi na zona urbana, o que corresponde a $82 \%$. Já, entre as mulheres, 10 trabalhadoras responderam que iniciaram as suas atividades na zona rural, o que corresponde a 59\%. Neste contexto, há uma diferença significativa e diversa entre os gêneros entrevistados.

No caso da internação nas clínicas de recuperação das "Obras Sociais - Padre Osvaldo", entre os trabalhadores do gênero 
masculino, quatro responderam que já estiveram em tratamento, equivalente a $36 \%$. Entre as trabalhadoras, a maioria absoluta respondeu que nunca esteve internada, o que corresponde a $100 \%$ das entrevistadas.

Quando perguntados se já fizeram ou fazem uso de algum tipo de bebida alcoólica, entre o gênero masculino, oito trabalhadores responderam que sim, o que corresponde a $72 \%$. Enquanto que no gênero feminino, apenas cinco trabalhadoras responderam que já fizeram ou fazem uso de bebida alcoólica, o que corresponde a $30 \%$ das entrevistadas.

Quanto ao uso de drogas, quando perguntados se já fizeram ou fazem: entre os trabalhadores, seis responderam que não, o que corresponde a 55\%. Enquanto que, no gênero feminino, apenas uma trabalhadora respondeu que já fez ou faz uso, o que corresponde a apenas $6 \%$ das entrevistadas.

\subsection{TRAJETÓRIAS SOCIAIS}

Este trabalho trata de alguns aspectos significativos, relacionados à construção das trajetórias ocupacionais dos entrevistados, ocupações essas desenvolvidas desde a entrada no mercado de trabalho, passando pela qualificação profissional, dificuldades enfrentadas na conquista de um trabalho, seus vícios e a reconstrução de suas vidas através do Projeto "Luxo do Lixo". O amplo conjunto de informações, obtidas por meio de depoimentos e relatos orais em torno do trabalho e da família, permitiu analisar alguns elementos constitutivos das trajetórias ocupacionais e familiares, articulados a processos sociais presentes na sociedade brasileira. Neste sentido, foi criada uma tabela (tabela 1) com o perfil dos trabalhadores do Projeto "Luxo do Lixo".

Os dados deste estudo apresentam vidas de muito trabalho. Dos entrevistados, tanto do gênero masculino, quanto do gênero feminino começaram a trabalhar, em sua maioria, na infância. A zona rural está representada po uma parcela significativa dos entrevistados, em geral nas lavouras de subsistência da família ou ajudando nos serviços da roça de pais ou avós, onde permaneceram nessas ocupações por cerca de 7 a 10 anos.

Sobre os trabalhadores que iniciaram suas atividades de trabalho nas cidades, dentre as respostas verificou-se que, em sua maioria, começaram: como empregadas domésticas, quando se trata do gênero feminino; e na indústria ou comércio, quando se trata do gênero masculino. 
Da análise do conjunto das trajetórias ocupacionais pode-se inferir duas ordens de questões. A primeira individual - diz respeito a como cada um, ao longo dos anos, veio perdendo oportunidades de trabalho, tendo em vista seu tipo de: formação, experiência profissional e até mesmo o contato com vícios. A segunda, de ordem mais geral - avalia que todos, sem distinção, têm no mercado as mesmas oportunidades precárias de trabalho, com forte rebaixamento salarial. Não há diferenciação para os mais velhos e mais novos e nem mesmo é levada em conta a formação ou a experiência profissional ao longo dos anos.

Tabela 1. Perfil dos Trabalhadores.

\begin{tabular}{|c|c|c|c|c|c|c|c|c|}
\hline Nomes & Sexo & Idade & $\begin{array}{c}\text { Estado } \\
\text { Civil }\end{array}$ & $\begin{array}{c}\text { Estado de } \\
\text { Origem }\end{array}$ & Filhos & Religião & $\begin{array}{c}\text { Esteve } \\
\text { Internado }\end{array}$ & $\begin{array}{c}\text { Tempo no } \\
\text { Projeto } \\
\end{array}$ \\
\hline S.N. & $\mathrm{M}$ & 54 & Separado & SP & 3 & Católica & Sim & 2 anos \\
\hline O.N & $\mathrm{F}$ & 43 & Solteira & SP & 1 & Evangélica & Não & 8 meses \\
\hline J.R. & $F$ & 45 & Solteira & $\mathrm{BA}$ & 7 & Católica & Não & 5 meses \\
\hline L.F & $\mathrm{M}$ & 30 & Solteiro & SP & 0 & Católica & Sim & 1 mês \\
\hline C.S. & $F$ & 34 & Solteira & SP & 3 & Católica & Não & 8 anos \\
\hline M.H. & $\mathrm{F}$ & 47 & Casada & SP & 4 & Evangélica & Não & 1 ano 4 meses \\
\hline S.M. & $\mathrm{M}$ & 60 & Casado & SP & 1 & Espírita & Não & 5 meses \\
\hline I.P. & $\mathrm{F}$ & 44 & Solteira & SP & 2 & Católica & Não & 4 meses \\
\hline P.O. & $\mathrm{F}$ & 24 & Solteira & SP & 4 & Católica & Não & 1ano \\
\hline D.B. & $\mathrm{F}$ & 43 & Separada & SP & 2 & Evangélica & Não & 4 meses \\
\hline L.P. & $\mathrm{F}$ & 47 & Casada & SP & 7 & Evangélica & Não & 3 meses \\
\hline I.C.S & $\mathrm{F}$ & 28 & Solteira & SP & 4 & Católica & Não & 1 ano \\
\hline J.C.S & $\mathrm{M}$ & 47 & Solteiro & SP & 0 & Católica & Não & 1 ano 6 meses \\
\hline L.M. & $\mathrm{F}$ & 28 & Amasiada & SP & 2 & Não Informou & Não & 4 meses \\
\hline J.S. & M & 50 & Casado & SP & 4 & Católica & Não & 4 meses \\
\hline R.M.S. & $F$ & 46 & Desquitada & $\mathrm{SP}$ & 3 & Católica & Não & 2 anos 1 mês \\
\hline V.V.T. & $\mathrm{M}$ & 50 & Separado & SP & 3 & Católica & Não & 3 meses \\
\hline Z.A.C. & $F$ & 46 & Solteira & SP & 2 & Católica & Não & 8 meses \\
\hline M.J.P. & M & 26 & Casado & SP & 0 & Evangélica & Não & 2 anos \\
\hline J.A. & $\mathrm{F}$ & 24 & Solteira & SP & 2 & Evangélica & Não & 1 ano \\
\hline V.O. & $\mathrm{F}$ & 48 & Solteira & SP & 7 & Evangélica & Não & 2 meses \\
\hline L.A.S. & $\mathrm{F}$ & 37 & Casada & $\mathrm{SP}$ & 3 & Evangélica & Não & 9 anos \\
\hline L.P. & $\mathrm{F}$ & 29 & Amasiada & SP & 3 & Católica & Não & 2 anos \\
\hline M.A.R & $\mathrm{F}$ & 25 & Solteira & SP & 0 & Evangélica & Não & 1 ano 6 meses \\
\hline R.C.N. & $M$ & 43 & Casado & SP & 1 & Católica & Não & 1 anol mês \\
\hline I.B. & $\mathrm{M}$ & 57 & Solteiro & PR & 0 & Católica & Não & 5 meses \\
\hline M.C.R. & $\mathrm{M}$ & 41 & Solteiro & SP & 0 & Evangélica & Sim & 8 meses \\
\hline C.R.S. & $\mathrm{M}$ & 23 & Solteiro & SP & 0 & Católica & Sim & 1 ano \\
\hline
\end{tabular}

Fonte: Pesquisa de campo. 
O nível de educação escolar sinaliza que, embora a resposta tenha sido satisfatória, apenas seis trabalhadores entre o gênero masculino e feminino possuem o segundo grau completo; os demais possuem até a $8^{\mathrm{a}}$ série, do primeiro grau. $\mathrm{O}$ baixo nível educacional é um obstáculo para a inserção no moderno mercado de trabalho, onde se faz necessária a utilização de máquinas e equipamentos que requerem leitura e interpretação de manuais.

A quantidade de filhos, entre os trabalhadores do gênero masculino, gira em torno de 2,4 por casal. Enquanto que a quantidade de filhos, entre as trabalhadoras do gênero feminino, varia de 3,5 por casal. No entanto, três trabalhadoras declararam durante a entrevista, ter sete filhos, enquanto que três trabalhadoras também declararam possuir quatro filhos cada.

Quando perguntados sobre o que fazem nas horas vagas, as respostas foram as mais variadas possíveis. Dentre o gênero masculino, dois trabalhadores responderam que executam pequenos reparos em suas casas, outros que gostam de caminhar, descansar e até ir visitar parentes. Dentre o gênero feminino, quatro trabalhadoras responderam que preferem cuidar dos filhos nas horas vagas, outras responderam que participam de bailes, festas com amigas, fazem bordados e até a leitura da bíblia.

$\mathrm{Na}$ fala dos trabalhadores em geral, registra-se o otimismo e a esperança com relação ao futuro, à conquista de direitos e à melhoria econômica através do Projeto "Luxo do Lixo". A organização e a reestruturação do Projeto "Luxo do Lixo", favoreceu a conquista do direito mínimo de acesso aos documentos e à profissionalização, já que o Projeto conta com uma empresa que iniciou seus trabalhos técnicos na área da segurança do trabalho e o apoio espiritual coordenado por Padre Osvaldo de Oliveira Rosa.

Todos os trabalhadores entrevistados relataram que estão satisfeitos com o serviço que exercem junto ao projeto e quando perguntados qual nota de 0 a 10 atribuem ao Projeto "Luxo do Lixo", apenas um trabalhador disse nota 8 , os demais atribuíram nota 10 . O trabalhador que atribuiu a nota 8 , disse não se conformar com sua situação pessoal, já que exerceu profissão de bancário, e hoje estava trabalhando com resíduos.

O coordenador geral do Projeto "Luxo do Lixo", disse que o trabalho de recolhimento e venda dos resíduos sólidos passa por um momento de crise, devido à queda dos preços. Os empresários locais, desde os donos de um pequeno mercantil aos donos de supermercados e algumas 
escolas, têm auxiliado e contribuído com o Projeto "Luxo do Lixo", no sentido de fornecimento da matéria-prima principal, ou seja, os resíduos sólidos.

Nas entrevistas foram identificados vários baixos indicadores das condições de vida destes trabalhadores: falta de oportunidades, desigualdade social e dramas familiares. Alguns trabalhadores encontram-se com profundos problemas financeiros e em condições precárias de moradia. Mas a organização e a oportunidade no Projeto "Luxo do Lixo" têm demonstrado ser um caminho possível para a superação da exclusão e construção da cidadania.

\subsection{TRAJETÓRIAS INDIVIDUAIS.}

São várias histórias. Histórias de vida de trabalhadores que se diferenciam ao mesmo tempo em que se aproximam. Existem resistências e desistências nessas histórias contadas. Histórias significativas de perdas e drásticas rupturas ligadas a separações, sentimentos, abandono familiar, problemas com alcoolismo e entorpecentes ilícitos, que provocam desespero e solidão. Experiências de luta, por uma vida melhor para si e para a família, são vividas a cada dia dando um novo sentido à vida, que sempre pareceu ameaçada pela incerteza do amanhã.
Vivem como se estivessem diante de um abismo entre um mundo de recordações e desejo de vida melhor. Um doloroso e inesquecível processo de perdas sentimentais, de emprego, de vínculos familiares e sociais, de auto-estima e de equilíbrio psíquico, mas que acima de tudo parecem estar renovando suas esperanças por estarem trabalhando num Projeto que, de certa maneira, busca reconstruir a nova identidade dos trabalhadores.

Parafraseando o sociólogo BAUMAN (2005, 2008, 2009), que trata dos mais diferentes dilemas do mundo contemporâneo, entre eles a exclusão, as diversas formas de exclusão: as histórias ajudam as pessoas na busca do entendimento, separando irrelevante do irrelevante, as ações ou atos de seus ambientes ou palcos, a trama de seus antecedentes e os heróis ou vilões que se encontram no centro do roteiro dos hostes de excedentes e simulacros. Sendo assim, traz-se para o presente trabalho, uma história que ilustra claramente um dos perfis dos trabalhadores no Projeto Luxo do Lixo. O nome do entrevistado é fictício, preservando o sigilo necessário a este tipo de pesquisa. 


\section{$\underline{\text { Mateus }}$}

“Trabalhar na rua não é muito bom também não, às vezes eles viam a gente que ia trabalhar, achavam que a gente ia roubar, que a gente era ladrão, que estava usando droga, que o dinheiro era pra droga. Que a gente não precisa não”.

Mateus convive com a sua companheira e dois enteados. Nasceu na cidade de Catanduva, interior do Estado de São Paulo. Começou a trabalhar na roça com treze anos de idade e o serviço era bastante "puxado", de sol a sol, ganhava pouco e sofria muito. Entre as maiores dificuldades que passou, durante o período que trabalhou na lavoura de café e laranja, foi quando quebrou o pé e outra vez quando quebrou a perna. Nessa época sempre morou com os pais e o irmão.

Quando deixou de trabalhar como lavrador, foi nas ruas da cidade de Catanduva que passou a recolher material reciclável - termo este mais conhecido na linguagem dos catadores e trabalhadores e por quase 10 anos essa foi sua principal atividade e fonte de renda. Das ruas, no tempo em que recolhia reciclável, Mateus não guarda boas lembranças, aliás, durante a entrevista ao ser perguntado sobre esse assunto demonstrou revolta, principalmente por ser muito discriminado e também humilhado pela população em geral.

\section{"A maioria das pessoas achava que o catador não precisava recolher reciclável, que aquilo seria vendido para comprar droga. Alguns até colaboram com a gente, mas têm outros, aliás, a maioria não”.}

Mateus aponta que os principais motivos, que o levaram a trabalhar com reciclável, foram: a dificuldade em conseguir um emprego com Carteira registrada e a falta de estudo e capacitação. Foi com o passar do tempo e o baixo valor pago pela indústria da reciclagem, que optou por deixar as ruas e viver de pequenos trabalhos ocasionais, como servente de pedreiro.

Em 2002, conseguiu um emprego, na então denominada cooperativa de material reciclável "Luxo do Lixo", como os salários atrasavam muito e a jornada de trabalho era estendida até por volta das dez e meia da noite, optou por voltar ás ruas. Foi nesse período em que deixou a cooperativa e, devido à dificuldade financeira, começou a se envolver com entorpecentes. Influenciado pelo que considera "má influência dos amigos", fez uso do crack por cerca de cinco anos. Como não tinha dinheiro para comprar, 
resolveu "trabalhar" na venda e entrega de entorpecentes; também vivia da prática de pequenos furtos para "manter o vício", até que "caiu" e foi preso pela polícia, o que considera "uma fase bastante ruim". Preso no Centro de Detenção Provisória (CDP), da cidade de São José do Rio Preto, interior do Estado de São Paulo, se sentiu abandonado pelos antigos "patrões" do tráfico.

"Tinha amigos entre aspas né, porque nessas horas dificeis do mundo some né. Nas horas ruins não tem ninguém não. Cadeia é ruim para caramba, só vendo pra crer mesmo".

A relação com a família, em especial a mãe, não foi nada boa. Alega que quando recebia visitas da mãe, ela: "só ia para falar mal". Sendo assim, por determinação dos demais detentos não pode mais recebê-la, ficando por quase um ano sem ver ninguém. A mãe só enviava alimentos ou outros produtos de higiene pessoal através de familiares e colegas de outros presos.

Embora pudesse contar com a boa vontade dos familiares dos outros presos, considera que a relação com os demais presos não era fácil, sendo bem complicada, uma vez que se deve respeitar o que é limitado e estabelecido dentro da prisão. Qualquer pessoa que venha aprontar qualquer coisa lá dentro, não “vai sair vivo".

"Tem muita coisa ruim, um matando o outro, matando pessoa envenenada. É uma coisa triste né”.

Foi após esse período que seu irmão, contando com o trabalho profissional de um advogado, conseguiu através de pedido judicial fazer com que Mateus ganhasse a liberdade das ruas, caso contrário teria que cumprir um período de quatro anos preso.

Quando ganhou a liberdade, foi trabalhar na rua e contou novamente com o apoio do irmão, que lhe emprestou uma carroça para que iniciasse a coleta de material reciclável. Passado algum tempo, auxiliou um rapaz como servente de construção por dois meses, após a entrega da obra procurou o Padre Osvaldo e voltou a trabalhar novamente no Projeto "Luxo do Lixo", foi quando "teve uma oportunidade para dar uma melhorada".

Durante a conversa, comparou o tempo em que trabalhava na cooperativa "Luxo do Lixo", que era mantida em sistema de cooperados, podendo demorar até 40 ou 50 dias para receber a sua parte. Quando o Padre Osvaldo assumiu a coordenação do Projeto "Luxo do Lixo", 
Mateus considera que "melhorou 100\%, agora o dinheiro vem certinho, não atrasa nenhum mês ou dia, inclusive com direito às férias, $13^{\circ}$ salário", como manda o figurino de um emprego normal. Recebe um salário de $\mathrm{R} \$ 800,00$ (oitocentos reais) e pretende voltar a estudar, a fim de concluir o segundo grau. Sobre a nota que aplicaria ao projeto, de uma escala de 0 a 10 , proferiu a nota 10 .

Em setembro, completou dois anos que Mateus está trabalhando no Projeto "Luxo do Lixo" e exerce a função de prensista. Evangélico não praticante, ele pretende voltar à igreja, "Deus é Amor", onde foi batizado e permaneceu por nove anos.

Dentre as atividades de lazer, gosta de levar as crianças no bosque, hoje, chamado de zoológico municipal e também para brincarem numa pracinha perto da sua casa.

Mesmo estando no Projeto "Luxo do Lixo", tem enviado alguns currículos para algumas empresas da cidade, mas considera que devido a sua prisão, seu nome ficou "marcado" pela sua ficha de antecedentes criminais, embora nunca mais tenha tido qualquer problema judicial.

Sobre a sua situação econômica atualmente, a considera muito boa em vista do que passou anteriormente e vê o futuro como uma coisa boa, tentando melhorar cada vez mais. Termina a entrevista dizendo: "Já tendo alguma coisa já é difícil imagine não tendo nada", referindose à necessidade de voltar a estudar.

Durante a entrevista, demonstrou muita tristeza na expressão e no olhar ao falar do período em que ficou preso e da dificuldade em encontrar um novo emprego. Percebe-se certa revolta para com a sociedade, ao falar do período em que trabalhou na rua. Neste sentido, a sua reinserção na sociedade após perder tudo, inclusive, o vínculo familiar, dá-se exatamente através do Projeto "Luxo do Lixo", que recicla resíduos descartados e seres humanos também descartados.

\section{CONSIDERAÇÕES FINAIS}

A pesquisa intitulada " $D a$ invisibilidade ao recomeço social: um estudo sobre trabalhadores do Projeto "Luxo do Lixo" em Catanduva/SP" teve como objetivo compreender o que levou esses trabalhadores, com seus dramas, histórias de vida e exclusão social, enfim, que se tornaram resíduos, sobras da economia de mercado, a trabalhar exatamente com o resíduo sólido produzido por esta economia. Trágica ironia.

Neste sentido, contextualiza-se que a falta de oportunidades no mercado de 
trabalho, os vícios, a baixa qualificação e os dramas familiares são resultados contundentes e marcantes desta exclusão social. Sendo assim, a questão que envolve a exclusão social, de acordo com os conceitos enunciados no início do texto, verifica-se no fato de ela estar muito presente na vida e na fala dos trabalhadores que constituem os sujeitos do presente trabalho.

Em sua fala, a maioria dos trabalhadores revela todo um contexto de exclusão, que acaba implicando em outras situações, como: estigmatização, 'falta' de cidadania, marginalidade, envolvimento com vícios etc.

O desenvolvimento das leituras e do trabalho de campo conduziu às caracterizações empíricas e à compreensão sobre o grupo formado por trabalhadores do Projeto "Luxo do Lixo". Este grupo de trabalhadores, por sua vez, contextualiza uma formação típica da modernidade tardia, etapa regida pelas lógicas simultâneas da sociedade de risco, dos consumistas e da busca de distinção/diferenciação por parte de seus segmentos. Como agentes sociais desse contexto, muitos trabalhadores experimentam processos muito contraditórios e ambivalentes na constituição de uma identidade social específica.
A pesquisa também permitiu sinalizar que a identidade dos trabalhadores do Projeto "Luxo do Lixo" encontra-se em formação, submetida às dinâmicas subjetivas, marcadas por processos repletos de contradições, tensões e fragilidades. Estes trabalhadores são resultados de uma condição de dupla exclusão: seja pela sociedade e dramas por que passaram; seja por serem excluídos no mercado de trabalho, uma vez que se evidencia que essas pessoas não tiveram o resgate necessário para viverem com dignidade. Sendo assim, o surgimento do Projeto "Luxo do Lixo" e a mudança de vida, poderá fazer com que esses trabalhadores voltem à busca de melhores condições de vida. É nesse ponto que é possível perceber a importância do consenso e dos pactos para que se possa construir um novo modelo social e de atividades, através do trabalho que vem sendo desenvolvido pela Associação "Pão Nosso - Obras Sociais Padre Osvaldo" para a realização do Projeto "Luxo do Lixo".

Quanto aos planos para o futuro, é comum o desejo de conseguir uma casa própria, voltar para a cidade de origem, comprar um carro ou moto, voltar a estudar ou qualificar-se, conseguir um emprego melhor.

Por último, cabe registrar que esta pesquisa sinalizou indicativos para futuros 
estudos sobre o tema, principalmente, no que diz respeito às histórias de vida de trabalhadores em situações cotidianas na cidade. Por outro lado, este estudo constitui uma tentativa de valorização do serviço prestado por um tipo específico de trabalhador, o reciclador dos resíduos produzidos em grande monta pela "sociedade de consumo", da qual ele faz parte apenas marginalmente, visto que também acabou descartado dentro dela.

Algo para se pensar a guisa de conclusão: o "lixo" não está fora, não é só aquilo que não se consome, não é só aquilo que foi lançado fora; o "lixo" é uma condição inerente à "sociedade de consumo", é a sua contraparte negativa, o outro lado da moeda, o seu lado muito feio, assim como o trabalhador que virou resíduo no mercado é o outro lado de uma sociedade que cada vez mais se divide entre os que têm e os que não têm, é um ser humano que perdeu seu viço.

\section{REFERÊNCIAS}

BAUMAN, Z. Vidas desperdiçadas. Jorge Zahar Ed., 2005.

Vida para o consumo. Rio de Janeiro: Jorge Zahar Ed., 2008.

Vida líquida. Rio de Janeiro: Jorge Zahar Ed., 2009.
BUARQUE, C. Admirável mundo atual - dicionário pessoal dos horrores e esperanças do mundo globalizado. São Paulo: Geração Editorial, 2001.

CÁRITAS Diocesana faz parceria para apoiar catadores de papel. O Regional, Catanduva, 26, fev., 1999. P.06-2 (Geral).

CASTEL, R. As metamorfoses da questão social: uma crônica do salário. Petrópolis: Vozes, 1998.

GALLO, Z. Ethos, a grande morada humana; economia, ecologia e ética. 1.ed. Itu (SP): Ottoni Editora, 2007.

LENOIR, R. Les exclus - Un Français sur dix éd. du Seuil. Collection Points Actuels, 1974.

NASCIMENTO, E. P. do. O fenômeno da exclusão social no Brasil. INED, n. 3, 1996.

QUINELATO, D, G. Da invisibilidade ao recomeço social: um estudo sobre os trabalhadores do Projeto "Luxo do Lixo" em Catanduva-SP. Dissertação de Mestrado. Programa de Mestrado em Desenvolvimento Regional e Meio Ambiente - UNIARA, 2012.

ROSA, C. M. M. Vidas de Rua. São Paulo: Hucitec, 2005 (Associação Rede Rua). 
ROSA, O. O. Projeto "Luxo do Lixo".

Catanduva, Paróquia Imaculada

Conceição, 09, set., 2011. Entrevista concedida a Davis Gláucio Quinelato.

ENDEREÇOS ELETRÔNICOS.

BRASIL. Governo do Distrito Federal.

Disponível em: <http://www.gdf.gov.br> Acesso em: 8 de maio de 2011.

CÂMARA MUNICIPAL DE CARANDUA - Catanduva/SP. Disponível em:

$<$ http://sapl.camaracatanduva.sp.gov.br/sap ldocumentos/normajuridica/3895texto_inte gral> Acesso em: 10 de junho de 2011.

CNBB, Conferência Nacional dos Bispos do Brasil. Cartilha História da Cáritas. Disponível em: < http://www.projetoreciclar.ufv.br/docs/cart ilha/polis_coleta.pdf > Acesso em: $12 \mathrm{de}$ julho de 2011.

PARÒQUIA IMACULADA CONCEIÇÂO - Catanduva/SP. Disponível em: <www.paroquiaimaculada.org.br > Acesso em: 28 de agosto de 2010.

$\underline{\text { LEI. }}$

Município de Catanduva.

Lei n ${ }^{\circ} 3.449 / 98$ - Autoriza o Município a celebrar Contrato de parceria com a Cáritas Diocesana de São José do Rio Preto e a Associação dos Catadores de Papel,
Papelão e Materiais Recicláveis de Catanduva para execução do Projeto de Reciclagem de Material denominado "Luxo do Lixo". 